\title{
LA RACIONALIDAD PRAGMÁTICA DE LA CREENCIA RELIGIOSA*
}

\section{THE PRAGMATIC RATIONALITY OF RELIGIOUS BELIEF}

\author{
ÁNGEL RIVERA-NOVOA \\ Universidad de Antioquia
}

Recibido: 15/01/2020 Aceptado: 24/04/2020

\section{RESUMEN}

En este artículo, defiendo que las creencias religiosas pueden ser pragmáticamente racionales. Una creencia religiosa es pragmáticamente racional si es consistente con una ética de las virtudes, como la de Martha Nussbaum, al margen de si tal creencia tiene evidencia o justificación como soporte epistémico. Para lograr tal objetivo, primero, analizaré algunas tesis pragmatistas y anti-evidencialistas de William James y Richard Rorty. En segundo lugar, analizaré el evidencialismo de William Clifford y Susan Haack. Luego, argumentaré que, aunque los argumentos evidencialistas son más fuertes que los anti-evidencialistas, es posible satisfacer las demandas de ambas posiciones. En particular, sostendré que la diferencia pragmática relevante descansa en garantizar que la creencia religiosa no implique daño moral. Finalmente, argumentaré que, para satisfacer las demandas evidencialistas y anti-evidencialistas, es necesario establecer un marco moral para cualquier cuerpo de creencias religioso.

* Agradezco los comentarios de Carlos Miguel Gómez, Juan Camilo Toro, Leonardo González y Andrés Buriticá a las versiones previas de este escrito. 
Palabras clave: Pragmatismo, racionalidad, justificación, creencia religiosa, evidencialismo, anti-evidencialismo, racionalidad pragmática.

\section{ABSTRACT}

In this article, I defend that religious beliefs can be pragmatically rational. A religious belief is pragmatically rational if it is consistent with an ethics of virtues, like Martha Nussbaum's, regardless if such belief has evidence or justification as epistemic support. In order to argue that, firstly, I will analyze some pragmatist and anti-evidentialist thesis from William James and Richard Rorty. Secondly, I will analyze the evidentialism of William Clifford and Susan Haack. Then, I will argue that, although evidentialist arguments are stronger than anti-evidentialist arguments, it is possible to satisfy the demands of both positions. In particular, I will hold that the pragmatist and relevant difference relies on ensuring that religious belief cannot implies moral damage. Finally, I will argue that, in order to satisfy both evidentialist and anti-evidentialist demands, it is necessary to establish a moral frame for any religious creed.

Keywords: Pragmatism, Rationality, Justification, Religious Belief, Evidentialism, Anti-Evidetialism, Pragmatic Rationality.

\section{INTRODUCCIÓN}

Es común dar por supuesto cierto vínculo entre la racionalidad de una creencia y su justificación epistémica. Según dicho vínculo, una creencia $\mathrm{P}$ es racional si y sólo si es justificable epistémicamente (sea a través de una inferencia lógica, por algún tipo de contacto empírico con el mundo o porque la creencia es autoevidente). A la tesis que vincula la racionalidad y la justificación epistémica se le denomina 'evidencialismo'. Ahora bien, suponiendo que el evidencialismo es cierto, ¿qué sucede con las creencias que catalogamos habitualmente como religiosas? Si alguien cree en Dios por fe - -i.e., sin apelar a algún tipo de evidencia-, ¿es esa creencia irracional?

En epistemología de la religión, el evidencialismo es un problema que demanda una solución por parte del defensor de la racionalidad de las creencias religiosas. Plantinga define el evidencialismo de la siguiente manera: "[e]videntialism is the claim that religious belief is rationally acceptable only if there are good argments for it" (Plantinga 2000, 83). De esta manera, todo religioso, de no apelar a una evidencia para el sostenimiento de sus creencias, será irracional 
dada la tesis del evidencialismo. Los movimientos ateístas y anti religiosos tienen un asidero argumentativo en contra de la racionalidad de las creencias religiosas: la acusación de que carecen de evidencia. La irracionalidad de la creencia religiosa se hace incluso más notoria si se compara el cuerpo de creencias de una religión particular con un sistema de creencias densamente justificado, como por ejemplo el de la física cuántica o el de la teoría de la evolución. El nuevo ateísmo, encarnado en las figuras de Dawkins, Dennett, Harris, Hitchens y otros, apela constantemente a la ausencia de evidencia de los sistemas de creencias religiosas para sostener un naturalismo fuerte y desterrar a la religión al terreno de lo irracional.

Una respuesta común para enfrentar la objeción del evidencialismo y salvaguardar la racionalidad de la creencia religiosa es tratar de argumentar, epistémicamente, a favor de ésta. ${ }^{1}$ Sin embargo, el propósito de este escrito es defender que las creencias religiosas pueden gozar de una racionalidad pragmática sin que necesariamente se deba apelar a algún tipo de justificación epistémica. El concepto de 'racionalidad pragmática' que deseo proponer surge de una necesidad práctica, esto es, los sistemas de creencias pueden juzgarse como racionales no necesariamente por su justificación epistémica, sino, a nivel más general, en virtud de la diferencia práctica que impliquen -que algunas puede ser idéntica a su justificación epistémica, pero no siempre-.

En esa medida, en un primer momento analizaré argumentos de orden pragmatista que intentan defender la idea de que es posible sostener creencias religiosas sin necesidad de proveer evidencia o justificación, sin que esto implique conducta irracional alguna por parte del creyente (James y Rorty). En segundo lugar, analizaré algunos argumentos que defienden que sostener creencias sin justificación es moral y pragmáticamente insostenible (Clifford y Haack). En una tercera parte, espero defender que, aunque las críticas de Clifford y Haack parecen ser contundentes sobre los anti-evidencialistas, es posible satisfacer simultáneamente las exigencias pragmáticas de parte y parte (i.e., el derecho a creer sin evidencia y la responsabilidad práctica y moral), si se tiene en cuenta

1 Un claro ejemplo de este proyecto filosófico es lo que se conoce como 'epistemología reformada', donde confluyen autores como Plantinga, Alston, Mavrodes, Wolterstroff, entre otros. Dicho movimiento parte de la idea de que la epistemología clásica está anclada en el fundacionalismo de la justificación, pero que una vez se renuncie a dicho fundacionalismo, hay diversas formas en que las creencias religiosas pueden ser consideradas como racionales (por ejemplo, si se asume que son creencias básicas). Alister McGrath es también un buen ejemplo de alguien quien cree que la justificación del teísmo, por ejemplo, no sólo es posible, sino que el teísmo sería la mejor explicación de la existencia del mundo empírico. Otros proyectos interesantes descansan en la psicología evolucionista y el confiabilismo e intentan mostrar que la justificación de la creencia religiosa está dada por su aporte evolutivo en la selección de grupos. 
que dichas exigencias son, justamente, de carácter práctico y no epistémico. Finalmente, con miras a sostener la idea de que el cumplimiento de ambas exigencias es consistente, desarrollaré la noción de 'racionalidad pragmática' de una creencia a partir de la propuesta de una ética de las virtudes no-relativas de Martha Nussbaum. De esta manera, espero sostener que una creencia religiosa es pragmáticamente racional si cumple con los criterios normativos establecidos por una ética de las virtudes, al margen de si la creencia está epistémicamente justificada o no. Así, además, sería posible pensar en sistemas de creencias religiosos, inconsistentes entre sí, pero que en virtud de su racionalidad pragmática puedan convivir.

\section{ANTI-EVIDENCIALISMO Y PRAGMATISMO}

En esta sección, me interesa dar cuenta de un tipo de respuesta a la tesis evidencialista. Este tipo de respuesta es pragmático, debido a que depende de una atadura conceptual entre la creencia religiosa y sus implicaciones prácticas. En general, dicho tipo de respuesta pretende argumentar que no por el hecho de que una creencia carezca de evidencia y justificación epistémica es legítimo atribuirle irracionalidad - respuesta que parece ir muy acorde con el propósito que me he trazado en este artículo-. Para ello, me centraré en las figuras de William James y Richard Rorty.

\section{JAMES Y LA VOLUNTAD DE CREER}

En "El significado del pragmatismo", James asegura que el pragmatismo es un método y una teoría de la verdad. En tanto método, el pragmatismo sirve para resolver disputas de carácter metafísico mediante el establecimiento de diferencias prácticas de las nociones que se hallan en disputa. Sólo en la esfera práctica es posible establecer si una disputa tiene o no sentido. Si un concepto o tesis filosófica no tiene ninguna manifestación en la vida práctica, entonces carece de sentido. Del mismo modo, si en una disputa teórica las tesis enfrentadas tienen las mismas consecuencias prácticas, entonces la disputa será sólo aparente (cf. James 1907a, 52-55). Además, el mismo método puede establecer la diferencia entre lo verdadero y lo falso. Dice James, "[s]i las ideas teológicas prueban poseer valor para la vida, serán verdaderas para el pragmatismo en la medida en que lo consigan" (James 1907a, 70). De esta manera, si es posible pensar que una creencia religiosa tiene valor para la vida, esto es, tiene profundas repercusiones prácticas en la vida del creyente, al margen de si es soportada por justificación epistémica alguna, no sería legítimo acusarla de irracional y podría ser 
considerada verdadera por un pragmatista. En últimas, si se prueba que una creencia es verdadera, desde el punto de vista pragmatista, entonces su sostenimiento será perfectamente racional sin importar si tiene soporte epistémico o no.

Justamente en su artículo "La voluntad de creer", James se propone defender que hay un derecho legítimo a creer en asuntos religiosos "a pesar de que nuestro intelecto meramente lógico no esté obligado a ello" (James 1897, 41). James, fiel a su método pragmatista, realiza una serie de definiciones y distinciones importantes. En primer lugar, llama 'hipótesis' a todo aquello que puede ser objeto de creencia. Ahora bien, hay hipótesis muertas e hipótesis vivas. Las hipótesis vivas son aquellas que tienen la posibilidad real (no sólo lógica) de ser creídas por un sujeto; las muertas no tienen esa posibilidad. El que una hipótesis sea viva o muerta depende, entonces, de una relación particular con el sujeto que se define en términos de la disposición a actuar con base en dicha hipótesis (cf. James 1897, 42). Lo anterior es importante porque, entonces, toda hipótesis viva marcará una diferencia en la práctica y James quiere argumentar que la hipótesis religiosa puede ser viva.

James llama 'opción' a la decisión que un sujeto toma ante dos hipótesis. Las opciones pueden ser divididas en varias categorías: 1) vivas o muertas, 2) forzosas o evitables y 3 ) trascendentales o triviales. Una opción viva es aquella que se da entre dos hipótesis vivas. Si alguna de las dos hipótesis es muerta, la opción entre ellas también lo será. Por su parte, la opción es forzosa si un sujeto debe optar por alguna de las hipótesis; por ejemplo, cuando un sujeto debe elegir entre $\mathrm{P}$ y No-P y no tiene a su disposición una forma de evitar la disyunción. Si la disyunción planteada pude resolverse con otras alternativas, la opción será evitable. Finalmente, la diferencia entre opciones trascendentales o triviales radica en si al menos una de las hipótesis constituye una posibilidad única para el agente. Si a un sujeto se le presenta la opción de ir en un viaje a la Luna, al menos en nuestro tiempo, para él la opción será trascendental, ya que es bastante probable que dicha oportunidad no se repita. Por el contrario, si alguna de las hipótesis no es una posibilidad única para el agente, cuando lo que hay en juego es insignificante o cuando la decisión puede ser reversible en el futuro, entonces la opción será trivial. James asegura que muchos de los desarrollos científicos atienden a opciones triviales. Una hipótesis que es viva para un científico, puede ser falseada en el camino de la investigación, caso en el cual el científico no habrá sufrido un daño vital, según James, sino a lo sumo sólo alguna pérdida de tiempo. James establece una última definición: una opción será genuina si es viva, forzosa y trascendental (cf. James 1897, 42-44). 
A partir de estas distinciones, James argumentará que tenemos derecho a creer sin evidencia cuando nos enfrentamos a una opción genuina. La primera condición, entonces, es que la hipótesis considerada sea viva. Si un hinduista planteara a un judío la posibilidad de creer en Brahmá, es probable que dicha hipótesis sea muerta para el judío, pues éste no es propenso a actuar bajo dicha creencia. Ahora bien, ¿por qué una hipótesis puede pasar de ser muerta a viva? James dice que esto se debe a que nuestra naturaleza volitiva no sólo se compone de deliberaciones conscientes sobre lo que se desea creer. Muchas veces, ciertos elementos como el miedo, la esperanza, el prejuicio, la pasión, la imitación, la admiración, el partidismo o la presión de nuestro entorno son factores decisivos para el establecimiento de creencias. Estos no son criterios epistémicos, pero están a la base de la naturaleza volitiva de aquello que creemos. Lo anterior tiene un muy importante vínculo con la visión pragmatista de la creencia. En efecto, aquello que es útil o marca una diferencia práctica en la vida se convierte en lo decisivo a la hora de aceptar una hipótesis: "no creemos en ningún hecho ni en ninguna teoría que no nos sirva para nada" (James 1897, 49). Por lo tanto, la aceptación o el rechazo de una hipótesis se da sobre la base de un criterio práctico, que a su vez no puede desligarse del ejercicio de la voluntad de creer. Los elementos evidenciales, lógicos y epistémicos no son los únicos relevantes en la formación de creencias (cf. James 1897, 48-50).

¿Pero esto basta para creer sin evidencia? James sostiene que, si las opciones son triviales, sería incorrecto creer sin evidencia, ya que en ese caso se puede posponer la búsqueda de la misma (en la labor científica, por ejemplo, ése es el camino más prudente). De igual manera, si la opción es evitable, es posible esperar hasta encontrar la evidencia relevante. ¿Pero qué sucede cuando la opción es, además de viva, forzosa y trascendental? Las cuestiones morales, según James, no pueden esperar a ser resueltas por algún tipo de prueba definitiva y su solución debe ser más o menos inmediata. La ciencia, señala James, habla de lo que existe, pero la moral habla de lo que sería bueno que existiera. En esa medida, "[h] ay casos pues en los cuales el hecho no puede producirse a menos que exista una fe previa en su producción" (James 1897, 64). Por ejemplo, sólo cuando se tiene fe en el trabajo del otro se pueden hacer proyectos en conjunto. Incluso la ciencia misma necesita de la fe, según James, pues si ésta no tiene fe en el valor de la objetividad y el poder de la prueba, la ciencia no podría desarrollarse en absoluto.

La hipótesis religiosa, en contraste con la científica o la moral, se define en virtud de las siguientes dos afirmaciones: 1) las mejores cosas son las más eternas y 2) nuestra vida será mejor si creemos que 1 es verdadera (cf. James 1897, 64). James propone estas dos características de un modo genérico: cualquier 
religión debería comprometerse con 1 y 2 a pesar de sus diferencias particulares. Para muchas personas la hipótesis religiosa puede ser muerta. Pero para quien resulta ser una hipótesis viva (y por tanto para quien la creencia marca una diferencia y tiene un valor en la práctica), también será una hipótesis trascendental, pues perder la oportunidad expresada en 2 es perder una oportunidad única. Además, la opción es forzosa, ya que incluso quien niega la opción (el escéptico que se abstiene de comprometerse con alguna de esas hipótesis), está tomando en serio una hipótesis de un orden superior (se abstiene o se compromete con alguna hipótesis). En otras palabras, el agnóstico y el escéptico no son inmunes a la elección entre 'creo que P' y 'no creo que P' (que es distinta a la proposición 'creo que no P'). A su vez, la afirmación "las mejores cosas son eternas" es una que no puede ser probada por la ciencia. En este caso, la fe es indispensable y legítima para resolver la cuestión y tenemos derecho a creer por voluntad y sin evidencia, siempre y cuando nos enfrentemos a una opción genuina (cf. James 1897, 64-68).

\section{RORTY Y EL CARÁCTER PRIVADO Y NO COGNITIVO DE LA CREENCIA RE-} LIGIOSA

Rorty es un gran crítico de la creencia religiosa y se considera afín a Habermas al considerar que el logro más importante de la Ilustración es haber secularizado la esfera pública. En esa medida, dice Rorty, un intelectual no encuentra en la religión una opción genuina, siguiendo la terminología de James. A lo mucho, el intelectual considera la religión como un asunto puramente privado. Por tal razón, los asuntos religiosos no deben ser puestos en la esfera pública, sino que el religioso debe tratar dichos asuntos en casa, como elementos que pueden contribuir a la búsqueda personal de sentido, pero que no deben influenciar en absoluto los asuntos políticos (cf. Rorty 1994, 168-167). Lo anterior debe ser así, según Rorty, por lo siguiente: "[t]he main reason religion needs to be privatized is that, in political discussion with those outside the relevant religious community, it is a conversation-stopper" (Rorty 1994, 171). En efecto, si alguien apela a creencias religiosas en un debate con alguien que no acepta tales creencias sin las pruebas necesarias, entonces la conversación se detiene de inmediato.

A pesar de lo anterior, Rorty acepta que las creencias religiosas puedan influir puntos de vista políticos. Lo que él rechaza es que, en la esfera pública, el 'argumento religioso' tenga lugar. Por ejemplo, en la esfera pública puede defenderse que no debe aceptarse la pena de muerte. Esta defensa puede estar motivada por creencias religiosas. Sin embargo, si la defensa de esta idea apela, en 
la esfera pública, a un mandato divino, entonces estamos ante un conversationstopper. Sin embargo, la defensa de dicha idea, aunque esté motivada por convicciones de corte religioso, puede darse siempre y cuando en la esfera pública la argumentación nunca apele a ningún tipo de autoridad religiosa. Un argumento en la esfera pública es uno cuyas premisas puedan ser sometidas a duda y escrutinio por parte de los interlocutores de una discusión, incluso si tales premisas surgen de contextos religiosos. Esto ocurre porque el aspecto relevante de la esfera pública es la justificación. En esa medida, de acuerdo con Rorty, no es irracional creer sin evidencia si y sólo si esas creencias se dan en un ámbito privado y no son traídas como elementos de autoridad en la discusión pública, ya que la única autoridad relevante en tal esfera será la aceptación intersubjetiva por parte de quienes están envueltos en una discusión.

Lo anterior además permite que no haya tensiones entre ciencia y religión. El objetivo de la ciencia es la descripción de fenómenos y la predicción de eventos futuros. La religión, en cambio, no tiene como fin ni la descripción ni la predicción, sino algo diferente, como la búsqueda de sentido. Dice Rorty: "the only role left for religious belief will be to help individuals find meaning in their lives, and to serve as a help to individuals in their times of trouble" (Rorty 2003, 142). Por tanto, los objetivos de la religión no están en conflicto con los objetivos de la ciencia, de tal manera que el creyente religioso no está obligado a dar justificación de sus creencias (cf. Rorty 2000a, 42-43). No obstante, de acuerdo con Rorty, puede formularse un tipo de objeción como la siguiente:

$[\mathrm{S}] \mathrm{i}$ hay conexiones inferenciales, entonces tenemos el deber de argumentar; si no hay, entonces no estamos tratando con una creencia en absoluto. [...] No existe ningún procedimiento por medio del cual una persona religiosa pueda reclamar el derecho de creer como parte de un derecho general a la intimidad, porque la actividad de creer es inherente a un proyecto público. [...] Todos tenemos la responsabilidad mutua de evitar creer algo que no pueda ser justificado ante el resto de nosotros. Ser racional es someter las creencias de uno - todas las creencias - al juicio de sus semejantes (Rorty 2000a, 44-45, énfasis mío).

Rorty cree que la respuesta de James a la objeción evidencialista es incompleta. Para superar dicha objeción, hay que echar abajo, de manera explícita, la distinción entre estados cognitivos y estados no cognitivos (entre creencia y deseo). Si se echa abajo tal distinción, entonces no hay un elemento que soporte la exigencia de que las convicciones religiosas deban argumentarse, simplemente por la apelación a su naturaleza cognitiva y por tanto inferencial y pública (cf. Rorty 1999, 154). Esto supone una exigencia pragmática adicional para el religioso. Con el fin de evitar su confrontación con la ciencia, el credo religioso 
debe interpretarse simbólicamente, esto es, debe estar libre de compromisos metafísicos como el dualismo mente/cuerpo, la inmortalidad del alma, la reencarnación, etc. La importancia de la creencia religiosa se da en virtud de su manifestación en las acciones del creyente y no en virtud de compromisos metafísicos de alguna naturaleza, caso en el cual necesitaría soportarse mediante evidencia epistémica. Al no brindar evidencia de los contenidos metafísicos de los diferentes credos, las religiones estarían nada más que imponiendo, en la esfera pública, un cúmulo de compromisos ontológicos. En otras palabras, quienes defienden el contenido metafísico de las creencias religiosas, sin brindar justificación epistémica de las mismas, quieren imponer un proyecto privado en la esfera pública (cf. Rorty 1999, 156-157).

Una buena filosofía pragmatista de la religión debe distinguir, según Rorty, entre fe y creencia. La creencia tiene contenidos proposicionales específicos mientras que la fe puede ignorar dichos contenidos particulares. Ésta es la diferencia entre un literalista y un simbolista. El literalista interpreta su fe como idéntica a sus creencias. El simbolista no. El pragmatista (simbolista) piensa que la religión no implica creencias con contenidos proposicionales particulares, sino que la creencia religiosa hace una diferencia en la vida humana (por ejemplo, por la presencia o ausencia de amor al prójimo). Los credos específicos, dice Rorty, deben ser abandonados para dar lugar a la fe, la cual no tendría un carácter cognitivo o proposicional ${ }^{2}$.

La distinción entre la esfera privada y la pública le permite a Rorty defender la idea de que la creencia religiosa puede sostenerse sin evidencia, cuando la creencia religiosa está enfrascada en proyectos personales privados. Eso supone no distinguir entre estados cognitivos y estados no cognitivos, lo que implica a su vez que la creencia religiosa es mejor interpretada como fe y no como creencia proposicional. Dice Rorty:

El hecho de que no la apoye la evidencia no es nunca una objeción contra la creencia religiosa. La única objeción que se le puede formular es la de que se

2 Wittgenstein comparte esta postura con Rorty. Según Wittgenstein, “[e]n un discurso religioso usamos expresiones como "Creo que sucederá tal y tal cosa", pero no las usamos en el mismo sentido en el que las usamos en la ciencia” (Wittgenstein 1966, 133). En efecto, para Wittgenstein la creencia religiosa no tiene condiciones de verdad o falsedad, esto es, no es proposicional: "[1]o característico, por el contrario, de las acciones rituales no es, en modo alguno, una opinión, una creencia que podría ser verdadera o falsa" (Wittgenstein 1967, 63). Para Wittgenstein, la creencia religiosa es una 'creencia inconmovible', lo que implica que funciona como un elemento a la que toda la vida de una persona debe ajustarse y que está alejada, completamente, del espacio de las razones. Como más adelante lo expondré, uno puede establecer ciertas objeciones a la idea de que las creencias religiosas no tienen un carácter cognitivo o proposicional. Para ver un rechazo a la postura de Wittgenstein, $c f$. Rivera-Novoa 2017. 
entromete en un proyecto cooperativo y social. [...] Tal intromisión no traiciona ningún tipo de responsabilidad hacia la Verdad o hacia la Razón, sino que traiciona la responsabilidad que uno tiene de cooperar con los demás seres humanos (Rorty 2000b, 60).

\section{EVIDENCIALISMO Y PRAGMATISMO}

Según lo dicho en la sección anterior, no sería irracional sostener creencias religiosas si y sólo si dichas creencias son la respuesta a una opción genuina (esto es, una opción viva, forzosa y trascendental) o la creencia religiosa se mantiene en un ámbito privado y podemos de alguna manera abandonar su naturaleza proposicional. En cualquiera de estos casos sería legítimo creer sin evidencia. En la presente sección, analizaré brevemente ciertas posturas evidencialistas con el objeto de ver posteriormente si las exigencias de tales concepciones anulan el derecho a creer sin evidencia aun en los casos mencionados. Para ello, me valdré de algunas ideas de William Clifford y de Susan Haack.

En su famoso artículo "La ética de la creencia", Clifford formula un caso de una persona que actúa sin tener en cuenta evidencia relevante. Formularé un caso análogo al de Clifford. Pensemos en una compañía aeronáutica que realiza vuelos privados. Durante mucho tiempo, el gerente de la compañía ha realizado vuelos exitosos y su compañía ha ganado cierta fama. Un día cualquiera, el gerente de la compañía advierte que uno de sus aviones tiene fallas eléctricas y mecánicas. Además, el gerente sabe que la carga de combustible del avión no cumple con el requisito mínimo de tiempo extra de vuelo para poder operar dada cualquier necesidad de estar más tiempo en el aire de lo inicialmente planeado. En resumen, el gerente de la compañía tiene evidencia suficiente que le muestra que el avión podría fallar. No obstante, el gerente ha realizado vuelos 'exitosos' con el mismo avión, con las mismas fallas y sin el combustible suficiente para enfrentar alguna emergencia. Lo anterior lo lleva a tener la profunda convicción de que el avión puede realizar el viaje sin ningún inconveniente. No obstante, sucede que en esta ocasión el avión no puede aterrizar a tiempo, su combustible se agota y todos los problemas mecánicos y eléctricos se manifiestan. El avión cae llevándose un importante número de vidas. En este caso, el gerente actuó sin ningún tipo de justificación para su convicción y, más aún, en contra de la evidencia relevante. Así, tendríamos que decir que actuar contra la evidencia (o sin la evidencia relevante) es irracional y, además, implica una irresponsabilidad moral. Dice Clifford: 
La pregunta sobre lo correcto o lo erróneo tiene que ver con el origen de esa creencia, no con el asunto sobre el que ésta versa; no de qué creencia se trataba, sino de cómo la alcanzó; no sobre si resultó ser verdadera o falsa, sino sobre si tenía derecho a creer de acuerdo con la evidencia en cuestión (Clifford 1877, 93).

Clifford intenta mostrar cuáles son las condiciones necesarias para tener una creencia de manera racional y responsable. Las condiciones en cuestión no son más que la evidencia que soporta la creencia. Sin una evidencia relevante, no se cumplen las condiciones mínimas para sostener una creencia. El problema es moral y radica justamente en la acción que sigue a la creencia. No basta con la convicción de la verdad de una creencia. Si tal creencia tiene implicaciones prácticas, entonces no debe escapar a un escrutinio epistémico para su sostenimiento, ya que "no es posible separar la creencia de la acción que ésta sugiere ni condenar la una sin hacer lo mismo con la otra" (Clifford 1877, 96).

Del mismo modo en que James y Rorty tienen una base pragmatista en su defensa del anti-evidencialismo, Clifford argumenta a favor de su evidencialismo acudiendo a la máxima pragmática según la cual no podemos desvincular la creencia de la acción. Ser responsable de una acción es ser responsable de una creencia. Para acertar moralmente, no podemos sostener creencias sin ningún tipo de evidencias, pues sus consecuencias prácticas son racional y moralmente reprochables. Sin importar el contenido de la creencia (puede ser de tipo religioso o no), creer sin justificación implica, de acuerdo con Clifford, daño moral. En últimas, la tesis de Clifford señala: "creer algo basándose en una evidencia insuficiente es malo siempre, en cualquier lugar y para todo el mundo" (Clifford $1877,102)^{3}$.

3 Vale la pena advertir que Clifford no ofrece un análisis de lo que cuenta como evidencia "suficiente". En la última parte del ensayo, Clifford señala en qué casos podemos creer en asuntos que sobrepasan nuestra experiencia, a saber, cuando aquello en lo que creemos no viola el principio de uniformidad de la naturaleza. En todo caso, la aproximación de Clifford parece ser tajante: o bien se tiene evidencia o no. Ciertas aproximaciones a la justificación de las creencias son, en contraste, de una naturaleza probabilística o bayesiana. En esa medida, sería interesante analziar el evidencialismo desde el punto de vista probabilístico, lo que daría como resultado un análisis gradual de la racionalidad de las creencias religiosas. Para un análisis de la relación entre justificación y probabilidad, $c f$. Pettigrew 2016, Smith 2017, Leitgeb 2017 o Moss 2018. Guy Axtell realiza un interesante análisis de la ética de la creencia en témrinos del grado de riesgo moral que involucra la creencia, de tal forma que el grado de racionalidad de una creencia religiosa se mediría en términos de la probabilidad de riesgo moral de la creencia ( $c f$. Axtell 2019). Agradezco a uno de los pares evaluadores de este texto quien me advirtió sobre esta posible línea de investigación acerca el problema del evidencialismo y la creencia religiosa. Por supuetso, un análisis de esta vía desbordaría los límites y los propósitos de este artículo. 
En contraste con la universalidad de la tesis de Clifford, de acuerdo con la cual siempre será moralmente malo creer sin evidencia, Susan Haack propone una tesis más moderada pero que, de igual forma, no deja bien librada a la creencia religiosa. La tesis de Haack, en todo caso, es tan evidencialista como la de Clifford. Dice Haack:

Like Clifford and unlike James, however, I think it is always epistemologically wrong to believe on inadequate evidence, in the sense that believing on inadequate evidence is always epistemologically unjustified. James's position is over-permissive epistemologically (Haack 2009, 355).

De esta manera, desde un punto de vista epistemológico, siempre es un error creer sin evidencia, de acuerdo con Haack. El distanciamiento con Clifford se produce desde el punto de vista ético. Haack defiende la idea de que la justificación ética y la justificación epistémica pueden sobreponerse, pero sólo parcialmente. En otras palabras, puede ser el caso que ambos tipos de justificación tengan una relación tan estrecha que, en ciertos casos, sean indistinguibles, pero esto no ocurre siempre (cf. Haack 2009, 345-346).

De acuerdo con Haack, en el debate entre James y Clifford se presupone una absoluta identidad entre la justificación epistémica y la ética, lo que parece llevar a la idea según la cual uno debe elegir entre los fuertes constreñimientos morales que Clifford impone a la creencia o la permisividad epistémica que James le otorga a la misma en relación con su justificación. Sin embargo, a diferencia de Cifford, Haack sostiene lo siguiente: "unjustified believing sometimes cause (at least prima facie) harm and sometimes be something for which the subject may properly be held responsible" (Haack 2009, 351). Así pues, la tesis evidencialista de Haack identifica justificación moral y epistémica no en todos los casos, sino sólo en algunos ${ }^{4}$. ¿En cuáles casos, según Haack, podemos atribuir responsabilidad moral cuando no estamos justificados en creer? Son casos en los cuales hay negligencia intelectual, ignoramos las pruebas de manera deliberada o caemos en una especie de pensamiento desiderativo. En estos casos hay una "ignorancia voluntaria" (willful ignorance). De esta manera, sostener una creencia como verdadera en ausencia de evidencia sería irracional cuando la creencia es producto de esa ignorancia voluntaria.

4 A pesar de las diferencias entre Clifford y Haack, me interesa rescatar su notable afinidad en cuanto a sus tesis evidencialistas. Los análisis recientes sobre la postura de Haack, su concepción de la ética de la creencia y su relación con Clifford tienden a acentuar demasiado la diferencia entre ambas aproximaciones casi sin considerar aquello en lo que están de acuerdo ( $c f r$ Nottelmann y Fessenbecker 2019, Axtell 2013 o Christian 2009). 
¿Qué sucede con la creencia religiosa? ¿Es, de acuerdo con Haack, la creencia religiosa un caso de creencia irracional y de ignorancia voluntaria? En "Point of Honor. On Science and Religion", Susan Haack recuerda la definición de James de creencia religiosa. Como se expuso anteriormente, para James una creencia religiosa es aquella que reúne las siguientes dos proposiciones: 1) las mejores cosas son las más eternas y 2) quien cree que 1 es verdadera vivirá mejor. El problema con dicha definición es que, en particular, la segunda proposición constituye un motivo para que el creyente caiga en una especie de pensamiento desiderativo (wishful thinking), ya que desear que algo sea verdadero (por las consecuencias o beneficios que ello pueda tener) no es, a los ojos de Haack, ninguna garantía para afirmar que la creencia sea verdadera. Aunque procedimentalmente el pensamiento desiderativo pueda funcionar, Haack dice que epistemológica y moralmente es insostenible. Por tanto, si la creencia es producto de pensamiento desiderativo y de ignorancia voluntaria, la creencia religiosa es entonces irracional, desde un punto de vista epistemológico y ético (cf. Haack 2003, 290-292).

Por tales razones, Susan Haack se declara incompatibilista en la disputa entre ciencia y religión. Para ella, hay sin duda tensiones profundas entre las visiones cosmológicas y biológicas actuales en contraste con los credos religiosos. La inconsistencia de tales visiones no es sólo aparente. Pensar que el ser humano es sólo un organismo que evolucionó en un medio habitable que se halla en una esquina de un inmenso universo no puede reconciliarse con la idea de que el ser humano, al ser creado por un ser superior, tiene un lugar especial en el universo. Pero más allá de las diferencias en cuanto a los contenidos de las creencias científicas y religiosas, a Haack le interesa resaltar, como a Clifford, las profundas diferencias en la formación misma de este tipo de creencias (cf. Haack 2019, 22-24).

En general, dice Haack, hay un profundo contraste entre el falibilismo de la ciencia, que se da en virtud de una evidencia empírica, y la fe religiosa, que se da muchas veces en virtud una revelación o una experiencia místico-religiosa. ¿Son comparables la experiencia religiosa con la evidencia de los sentidos? Haack piensa que la respuesta es negativa. La experiencia, dice Haack, nos provee información acerca de cómo son las cosas que tenemos a nuestro alrededor. Por otra parte, es obvio que nuestra experiencia está limitada por muchos factores y puede hacernos equivocar si las circunstancias de observación no son óptimas o si hay fallas en nuestros aparatos perceptuales. Sin embargo, la experiencia es la fuente informativa sobre el mundo y con base en ella trabajamos. Es la experiencia la que juega un rol evidencial en la formación de nuestras creencias más básicas e incluso en el aprendizaje de nuestro lenguaje. Al igual 
que nuestras creencias empíricas básicas, las creencias científicas tienen soporte evidencial en la experiencia. Por supuesto, las observaciones que soportan las teorías científicas muchas veces están mediadas por instrumentos sofisticados de observación que, al igual que nuestros sentidos, son falibles. Pero es a través de la experiencia que tenemos información de nuestro mundo. En contraste, la experiencia religiosa de Dios, por ejemplo, no tiene ningún órgano sensorial que sirva como medio. Solamente una minoría ha tenido tales experiencias y tan sólo una élite, que está compuesta por personas que ya han muerto en su mayoría, ha sido tomada seriamente, según Haack ${ }^{5}$. Por esa razón, la experiencia mística no puede jugar el mismo rol evidencial de la experiencia sensorial con la que la ciencia funciona (cf. Haack 2019, 24-27).

La ciencia, más que un conjunto de creencias, es un proyecto: un gran proyecto de investigación. La religión, en cambio, es un credo. La primera es consciente de su falibilidad, mientras que la segunda apela a la fe y al pensamiento desiderativo (cf. Haack 2003, 266-267). En esa medida la ciencia tiene un compromiso inherente con lo que Haack denomina 'honestidad intelectual':

Decir que el falibilismo "es inherente a la empresa científica" significa simplemente que la ciencia es un tipo de investigación, y que la voluntad de la ciencia de tomar la evidencia negativa seriamente es un aspecto importante de la honestidad intelectual exigida de cualquier investigador genuino. Y decir que la hoestidad intelectual requiere la voluntad de tomar la evidencia negativa seriamente simplemente significa que la evidencia negativa no debe ser ignorada o suprimida (Haack 2019, 31-32).

La honestidad intelectual, esto es, el buscar siempre evidencia favorable para el sostenimieto de creencias y el no ignorar la evidencia negativa es epistémica y moralemente valioso. Es epistémicamente valioso, porque hace avanzar las investigaciones por el camino correcto y refleja una búsqueda genuina de la verdad. Además, dicha integridad es moralmente valiosa, porque devela la honestidad que hay detrás de la creencia. Creer sin evidencia, o ignorando la evidencia en contra, es para Haack un error no sólo epistémico, sino moral (cf. Haack 1995, 58-59).

La falta de integridad y honestidad intelectual, así como el pensamiento desiderativo y la ignorancia voluntaria, implica la formación de pseudocreencias: "aquellos estados psicológicos familiares de lealtad obstinada a una proposición de la que uno sospecha a medias que es falsa, y la atadura sentimental

5 Para ver una crítica al argumento de Haack según el cual hay un continuo entre el sentido común y la ciencia y una discontinuidad entre el sentido común y la religión, $c f$. Caruana 2012. 
a una proposición a la que uno no le ha dedicado ningún pensamiento en absoluto" (Haack 1995, 55). En esa medida, una creencia religiosa que se sotiene sin evidencia es, a la luz de la argumentación precedente, irracional y moralmente errrónea, pues deliberadamente pasa por alto toda evidencia en contra posible, lo que a su vez hace explícito una falta de honestidad intelectual.

\section{PROBLEMAS DEL ANTI-EVIDENCIALISMO}

Una vez expuestos tanto los argumentos evidencialistas como los anti-evidencialistas, mi propósito en esta sección es mostrar que los primeros parecen derrotar a los segundos. Por un lado, recordemos los casos en los que, según los anti-evidencialistas expuestos, sería legítimo creer sin evidencia y sin que ello implique ser irracional. Creer sin evidencia sería posible si, o bien nos enfrentamos a una opción genuina, o bien la creencia hace parte de la esfera privada de un sujeto y no representa en sí algún estado cognitivo (i.e., algún compromiso con un contenido proposicional concreto). Por otro lado, los evidencialistas dirán que la creencia religiosa es irracional porque implica cierto tipo de daño moral (en diferentes niveles). Presentaré un caso relativamente reciente, y que tipifica una clase bastante común de acciones fundamentalistas en la historia de las religiones, para poder sopesar ambas posturas.

Durante la celebración del año nuevo de 2017 en una lujosa discoteca de Estambul, a orillas del Bósforo, un hombre irrumpió con un arma con la que disparó cerca de 150 veces durante 7 minutos. El ataque cobró 39 víctimas mortales y 65 heridos. Al siguiente día, el Estado Islámico, mediante diversas redes sociales, promulgó un comunicado en el que se adjudicaba el atentado, utilizando términos políticos y religiosos. Parte del comunicado señala:

En la continuación de las benditas operaciones que el Estado Islámico está llevando a cabo contra el protector de la cruz, Turquía, un heroico soldado del Califato golpeó una de las discotecas más famosas donde los cristianos celebran su día de fiesta apóstata (Citado de Hurtado 2017).

Tales palabras revelan varias cosas. En primer lugar, llaman 'bendito' a un ataque terrorista que costó la vida de personas. En segundo lugar, llaman a Turquía 'protector de la cruz', haciendo clara alusión a lo que el Estado Islámico considera como una doctrina hereje y pagana asociada con países occidentales que profesan ampliamente el cristianismo y con los cuales mantienen constante confrontación. Al asesino lo llaman 'heroico soldado del Califato'. Finalmente, describen el objeto del ataque como un lugar al que acuden los cristianos que 
celebran fiestas 'apóstatas'. El mensaje culmina haciendo un llamado a la realización de masacres semejantes:

Llamamos a todo verdadero muwahid [monoteísta estricto] a atacar las bases de los apóstatas, seculares, el Estado turco donde sea, incluidos seguridad, ejército, economía, medios de comunicación, y cada consulado y embajada que los represente sobre la faz de la Tierra (Citado de Zambrana 2017).

En estas palabras se revela el vínculo que el Estado Islámico realiza entre profesar un credo (ser un monoteísta estricto) y realizar tales tipos de actos dirigidos, en primer lugar, a apóstatas y seculares, para finalmente hacer de toda representación turca un objetivo de ataques terroristas —el hecho causó aún más alarma por ser el primer atentado a Turquía aceptado por el Estado Islámico- . Por supuesto, hechos como estos no son propios o exclusivos del Islam —o algo que se hace llamar 'Islam'- . Hechos semejantes se han realizado en nombre de innumerables credos. También es verdad que dichos eventos pueden tener una lectura política. Pero la conexión con la creencia religiosa parece muy clara. Al menos, el lenguaje religioso que se usa allí es explícito. Más allá de si las motivaciones de quien realiza el comunicado son religiosas o no, el que se haga uso de un lenguaje religioso exhibe cómo el credo puede ser atado a la acción —que en este caso es claramente repudiable.

Ahora bien, analizaré este caso a la luz de las condiciones que los antievidencialistas proponen para poder creer sin evidencia, con el fin de examinar si algún tipo de racionalidad podría ser atribuida en este caso. Comencemos por James y su voluntad de creer. De acuerdo con él, tenemos derecho a creer sin evidencia cuando nos enfrentamos a una opción genuina. La pregunta entonces es si, para el sujeto que realizó el atentado, realizarlo es de alguna forma la respuesta a una opción genuina. Siguiendo a James, podemos suponer que el sujeto podría tener el siguiente conjunto de creencias relacionadas entre sí:

1. Las mejores cosas (en este caso Alá) son las más eternas.

2. Se debe procurar hacer todas las cosas que agraden a Alá (lo mejor y más eterno).

3. Alá rechaza al incrédulo y acoge al creyente.

4. Dado 1,2 y 3, se debe procurar asesinar a quien no promulgue a Alá como su Dios.

5. Nuestra vida será mejor desde ahora si creemos que 1 es verdadera.

Por supuesto, James sólo aceptará como religiosas las creencias que él propuso (1 y 5) y quizás también la 2 . Sin embargo, no es difícil pensar que un sujeto podría creer 2, 3 y 4 como algo que apunta a procurarse las mejores y más eternas cosas (el agrado de Alá), ya que de hecho son las creencias que hacen 
parte del adoctrinamiento fundamentalista. Además, demos por hecho que las cinco creencias son creídas por fe. Podemos suponer que para dicho sujeto la hipótesis y la opción de matar en nombre de Alá es viva. Dado su contexto, su adoctrinamiento y sus motivaciones, el sujeto claramente está en disposición de actuar bajo este tipo de creencias. En segundo lugar, la opción es forzosa para el sujeto, pues debe elegir entre asesinar o no en nombre de Alá. Finalmente, la hipótesis será trascendental para el sujeto, pues ganarse el favor de Alá será para él sin duda una oportunidad única.

Tenemos, entonces, un caso en el que, sin duda, calificaríamos la creencia como irracional, a pesar de que cumple con las exigencias expuestas por James. De hecho, es posible pensar que un sinnúmero de acciones fundamentalistas pueden cumplir con dichas exigencias, por lo que o bien debemos abandonar los criterios de James (y aceptar que no es racional creer sin evidencias), o bien debemos ajustarlos de alguna manera para llevar las creencias fundamentalistas al terreno de lo verdaderamente irracional.

Finalmente, quiero argumentar que Rorty, aunque parece poner criterios que no permitirían legitimar al fundamentalista, hace demasiado exigente la creencia religiosa para un religioso promedio - lo que en últimas haría casi imposible el ejercicio y la práctica de cualquier religión-. En primer lugar, el requisito rortyano de que la religión debe ser un asunto privado parece no tener condiciones de satisfacción. ¿Cómo exigirle a un religioso que tenga sus creencias, y por tanto normas y hábitos de acción, solamente de las puertas de su casa para adentro? ¿Qué tipo de acciones podría provocar una creencia privada en ese sentido? Si las creencias son hábitos de acción, parece que no es pragmáticamente sostenible exigirle a un grupo de creencias que se mantengan y aíslen en un ámbito privado. Más aún, si la discusión y consecuente aceptación intersubjetiva es para Rorty el único criterio normativo posible, entonces las creencias religiosas como él las concibe no serían ni racionales ni irracionales, ya que no tendrían siquiera la posibilidad de un escrutinio público. El punto es que es muy complicado concebir que la creencia religiosa no tenga una influencia en la vida pública de una persona. Si las creencias religiosas son los lentes con los que un creyente ve el mundo, ¿cómo puede quitárselos cuando salga de su casa? El amor al prójimo de un cristiano, por ejemplo, sería impracticable. Concuerdo con Clifford cuando señala lo siguiente:

Ninguna creencia real, por nimia y fragmentaria que pueda parecer, es realmente insignificante: nos prepara para recibir otras como ella, confirma aquellas previas que se le parecen y debilita otras; y además va preparando una sigilosa conexión entre nuestros más íntimos pensamientos que puede en algún 
momento estallar en un comportamiento público y dejar su marca en nuestro carácter para siempre. Una creencia de una persona no es de ningún modo un asunto privado que le concierne sólo a ella (Clifford 1877, 96-97).

El ideal rortyano, aunque no legitima la racionalidad del fundamentalista, deshace la posibilidad misma de la creencia religiosa, al exigirle su privacidad. Por otro lado, la segunda exigencia de Rorty que demanda que la creencia religiosa socave la distinción de lo cognitivo y lo no cognitivo y abandone el credo para dar lugar a un estado no representacional, también parece impracticable por parte de un creyente promedio. Rorty asegura que sólo abandonando el carácter proposicional de la creencia, quitándole sus condiciones de verdad, será posible eximirla de justificación epistémica. No obstante, pensar que el creyente promedio de una religión no tiene creencias de naturaleza ontológica y metafísica es también desconocer la realidad de lo que promulgan las religiones. La reencarnación del alma, la inmortalidad de la misma, el estado de nirvana, la existencia de Dios, ángeles y demonios, la vida después de la muerte, la conversión del pan en cuerpo de Cristo y del vino en su sangre, los milagros, entre otro tipo de eventos, son presupuestos ontológicos de las religiones. La creencia religiosa que Rorty acepta, aunque posible para un cierto sujeto (para el politeísta romántico que él promulga), es inaceptable para la mayoría de creyentes. ${ }^{6}$

Con James y Rorty, y su asociación pragmática de creencia y acción, parecía abrirse la posibilidad de defender el derecho y la racionalidad de creer sin evidencia. No obstante, con Clifford y Haack tenemos una crítica que, siguiendo la misma intuición pragmatista de sus rivales, pone en un mismo nivel a la justificación epistémica y a la moral. Tal asociación cierra las puertas que parecían abiertas por los anti-evidencialistas, pues James no puede deslegitimar creencias y acciones de tinte religioso que calificamos sin duda como irracionales. Sus criterios y estándares no son suficientes para enfrentar el evidencialismo de Clifford y Haack, quienes reclaman, legítimamente, que la racionalidad de la creencia debe asegurase en términos epistémicos si no se quiere infligir un daño moral. Con Rorty, aunque salvaguardamos criterios de racionalidad que le permiten a un religioso creer sin evidencia y aseguramos que el fundamentalista sea calificado como irracional, imposibilitamos la práctica de las religiones habituales. No obstante, el anti-evidencialismo tiene una opción adicional, que es la que ahora deseo explorar.

6 Para un análisis más detallado sobre los problemas de la postura de Rorty acerca de la creencia religiosa, $c f$. Rivera-Novoa 2020. 


\section{LA RACIONALIDAD PRAGMÁTICA DE LA CREENCIA RELIGIOSA}

El hecho de que frente a un caso como el del fundamentalista la aproximación evidencialista supere a su contraria es debido al modo en que Clifford y Haack han abordado el problema de la racionalidad de la creencia. Para ellos la racionalidad epistémica no puede desligarse de la racionalidad moral. En esa medida, cuando actos fundamentalistas, basados en creencias sin evidencia, tienen consecuencias morales indeseables, calificamos la acción y la creencia como irracionales y demandamos de la creencia una evidencia o justificación que la soporte. No obstante, el precio a pagar parece ser muy alto: creer por fe sería un acto ilegítimo. ¿Qué pasa en este caso con los creyentes religiosos que, aunque no causan daño moral, no tienen evidencia epistémica que soporte sus creencias? ¿Son tan irracionales como el fundamentalista?

En este punto, vale la pena preguntarse qué es lo que está en juego y qué es lo que realmente importa cuando evaluamos la racionalidad de la creencia religiosa. En último término, el caso del fundamentalista nos muestra que lo relevante pragmáticamente a la hora de hablar de la racionalidad de la creencia religiosa son sus consecuencias morales. Lo que quiero sostener es que es posible separar la racionalidad epistémica de la justificación moral a la hora de evaluar la racionalidad de la creencia. Si lo que verdaderamente importa es la consecuencia moral de una creencia, quizás es posible afirmar que es racional sostener creencias sin evidencia o justificación si y sólo si esas creencias no tienen como consecuencia algún tipo de daño moral. No importa si un creyente es incapaz de demostrar la existencia de Dios o dar evidencia empírica de los milagros; lo que realmente importa es que la creencia en Dios o en los milagros no socave la integridad humana y moral de nadie.

Llamaré 'racionalidad pragmática' a la propiedad de una creencia religiosa de, en ausencia de evidencia, no afectar moralmente a nada ni a nadie. La etiqueta de 'racionalidad pragmática' de la creencia religiosa la utilizo porque la racionalidad puede no depender esencialmente de asuntos epistemológicos, sino que puede tener sus raíces en asuntos prácticos de otra índole. Si esto es cierto, un creyente podría sostener racionalmente, sin justificación y por fe, creencias de orden religioso. Sin embargo, es claro que la racionalidad debe atender a criterios normativos. Pero tales criterios no justifican epistémicamente la creencia, es decir, no hablan a favor de su verdad. De ahí que la separación de lo epistémico y lo ético nos permita hablar de que la creencia es racional, siempre y cuando encontremos un marco normativo que nos satisfaga pragmáticamente. Si mi intento es exitoso, tendrá la virtud de satisfacer simultáneamente las demandas evidencialistas tanto como las anti-evidencialistas. Las primeras exigen 
que la creencia de un agente no inflija daño moral alguno para que sea racional. Las segundas intentan reivindicar nuestro derecho a creer por fe o, en otras palabras, a tener libertad de conciencia religiosa. Por tanto, si es posible garantizar un marco normativo moral, no epistémico, al que una creencia pueda aferrarse, la racionalidad pragmática de la creencia religiosa será posible y constituiría una noción de 'racionalidad' más adecuada que las concepciones de racionalidad que subyacen a las tesis evidencialistas y anti-evidencialistas analizadas anteriormente.

El marco normativo moral al que quiero acudir como base de la racionalidad pragmática de una creencia religiosa lo tomaré prestado de la propuesta ética de Nussbaum. Nussbaum, inspirada en Aristóteles, formula lo que denomina una 'teoría de las virtudes no relativas'. La formulación de dicha teoría nace de su deseo de conciliar dos posturas que en las discusiones contemporáneas parecen incompatibles. Por un lado, muchos creen que la apelación a una ética de las virtudes, en contraste con la promulgación de una ética utilitarista o kantiana, trae la discusión a un terreno más concreto, alejado de la abstracción del cálculo del bienestar general o la objetividad de las reglas de acción. Sin embargo, una ética de este corte parecería implicar el relativismo, pues una ética de las virtudes parece basar las normas de acción en modos de vida particulares, donde se cultivan virtudes de carácter local. La intención de Nussbaum es armonizar la ética de las virtudes con una concepción universal de la misma y que sea aplicable transculturalmente (cf. Nussbaum 1996, 318-321).

El relativista, al ver la cantidad de contextos, culturas, hábitos y valores, piensa que las virtudes surgen debido al contexto cultural en el que se promueven. De hecho, al revisar la lista de virtudes y vicios de Aristóteles, el relativista lo acusa de que lo que ha hecho no es más que la proyección de un modo de vida particular: el griego. Nussbaum, por su parte, cree que Aristóteles en realidad está haciendo una descripción más amplia de aquello que podría estimular el florecimiento humano. Como indicio de ello, Nussbaum recuerda que muchos de los vicios y virtudes, explicitados por Aristóteles, carecen de nombre. Recuerda también que muchos de los nombres utilizados por Aristóteles se han usado de manera arbitraria, como extraídos de su propia cultura, advirtiendo que con cada uno de tales nombres quiere decir algo distinto a lo que en su contexto se quería significar con ellos. Además, el modo en que Aristóteles introduce su lista de vicios y virtudes responde a una identificación previa de distintas áreas de la experiencia humana que son independientes de su contexto. A cada una de esas áreas, Aristóteles le asigna una forma adecuada y otra errada de elección (virtud y vicio). 
Siguiendo la metodología aristotélica, Nussbaum propone una lista de las esferas de la vida humana que la ética de las virtudes debería promover, a través del desarrollo de una lista de capacidades asociadas. Nussbaum reconoce que su lista es intuitiva y puede sin dudas ampliarse y ajustarse. No obstante, lo interesante de su enumeración es que pretende reunir cierto número de experiencias que todo humano desea fomentar en tanto capacidad, con independencia de su cultura, pero que al interior de cada contexto, puede interpretarse de maneras disímiles. Esto permite encontrar los rasgos comunes a todo ser humano, sin desconocer las diferencias particulares de los diferentes tiempos y culturas. La lista de los ámbitos humanos enumerados por Nussbaum, con su correspondiente capacidad, es la siguiente:

Mortalidad. Todo ser humano se enfrenta a la muerte, aunque ésta se interprete de manera diferente dependiendo de la cultura. La capacidad que debe fomentarse en esta área es la vida (al menos hasta el punto en que valga la pena vivirla).

Cuerpo humano. La capacidad que debe fomentarse es la salud.

Placer y dolor. Todo ser humano goza de ellos. La capacidad asociada en tal caso es la integridad física.

Razón y cognición. Todo ser humano goza de ello. Las capacidades asociadas a esta área son la imaginación, el pensamiento y los sentidos.

El desarrollo infantil. La capacidad a cultivar en este caso son las emociones. Nuestro desarrollo emocional es fundamental para la vida como un todo.

Razón práctica. Todo ser humano realiza planes, se traza objetivos, metas y se pregunta por los medios adecuados para lograrlas. Su fomento es esencial para la vida.

Afiliaciones con otros seres humanos. La naturaleza del hombre es social y necesita de la creación de vínculos familiares y políticos. Para esta área, será necesario promover la posibilidad misma de las relaciones sociales, así como mecanismos que vayan en contra de cualquier tipo de discriminación.

La relación con otras especies y la naturaleza. Todo hombre es consciente de que no es la única especie existente y que tiene una relación con la naturaleza de apoyo y supervivencia. La posibilidad de dicha conexión debe garantizarse. 
Juego y humor. Es un ámbito de la experiencia que nos identifica como humanos. La negación de su posibilidad significaría también la decadencia del hombre; por tanto, debe promoverse dicha capacidad.

La individualidad. Cada ser humano es particular y tiene derecho a crear su entorno inmediato de modo tal que satisfaga el estímulo de sus capacidades de la mejor manera, sin ningún tipo de coacción o restricción de la libertad (cf. Nussbaum 1992, 212-222).

Una de las tesis pragmatistas que más identifican a un seguidor de dicha doctrina es el hecho de que todos los asuntos importantes lo son en tanto tengan una estrecha relación con los asuntos humanos. He decidido seguir a Nussbaum y su propuesta de las virtudes no relativas, porque justamente el enfoque de las virtudes y las capacidades es impensable al margen de la preocupación por lo puramente humano. En ese sentido, es pragmáticamente relevante. Rorty, en su afán por ser fiel a esta tesis pragmatista, quiso alejar todo rasgo de universalidad, en tanto que veía en éste un sometimiento a asuntos no humanos. No obstante, el listado de Nussbaum (que por supuesto puede ser mejorado, refinado y mejor definido) muestra que es posible pensar en una universalidad puramente humana, sin que eso implique desconocer diferencias culturales; justo ahí radica su riqueza.

Ahora bien, más allá de realizar un examen exhaustivo de cada una de las virtudes y capacidades anteriormente descritas, me interesa argumentar que si una creencia religiosa es consistente con dicho listado, aunque carezca de evidencia epistémica, puede ser considerada como racional. En efecto, si una creencia religiosa no atenta contra la vida, contra la integridad física, emocional, racional, social, política, cultural e individual de un ser humano, seguramente no tendremos ningún problema con dicha creencia religiosa, aun cuando no esté soportada en evidencia empírica o algún otro tipo de justificación. De esta manera, formularé mi tesis del siguiente modo:

Racionalidad pragmática: una creencia religiosa es pragmáticamente racional si es consistente con una ética de las virtudes no relativas, al margen de si está soportada evidencialmente.

La racionalidad pragmática de la creencia religiosa, definida así, permite, como se anunció, la satisfacción de dos demandas prácticas particulares: nuestro derecho a creer por fe y la prohibición del daño moral a costa del credo. Si la racionalidad de la creencia debía garantizarse por su conexión con la práctica, en sentido moral, toda creencia que cumpla con el 'test' de una ética de las virtudes no relativas podrá ser considerada racional. Un trabajo interesante 
consistiría en examinar conjuntos de creencias religiosas y someterlas al escrutinio de dicho test, para evaluar su racionalidad pragmática.

Ahora bien, ¿por qué llamar 'racional' a una creencia que sea consistente con una ética de las virtudes? ¿Acaso dicha consistencia no habla sólo a favor del acierto moral de la creencia? El punto que quiero resaltar es que violar el marco normativo moral propuesto de manera consciente implica una contradicción, de modo tal que su violación implica de inmediato irracionalidad. En efecto, una creencia religiosa que intente socavar la dignidad de otra persona, lo hace fundamentalmente defendiendo el desarrollo de alguna de sus capacidades propias. Por ejemplo, un fundamentalista religioso, en aras de desarrollar su individualidad, puede socavar la individualidad de otros, así como su integridad física e incluso su vida. Así, al intentar fomentar el florecimiento de la vida humana, lo que hace la creencia fundamentalista es destruir la vida humana misma. En esa medida, la violación del marco moral propuesto implica contradicción e irracionalidad. Bajo esta perspectiva, es contradictorio tener la creencia de que se tiene derecho a asesinar a alguien en nombre de un credo propio.

\section{CONCLUSIÓN}

Las consideraciones epistémicas de la creencia religiosa, en algunos casos, no son necesarias a la hora de atribuir racionalidad a la creencia. No importa si una creencia religiosa carece de evidencia; si dicha creencia no causa daño moral, podemos atribuirle racionalidad. Así mismo, una creencia religiosa que, por ejemplo, goce de buena evidencia y lleve a la acción de un modo instrumentalmente adecuado en la relación medios-fin, pero que socave la ética de las virtudes, será considerada irracional. Las consideraciones epistemológicas son irrelevantes para la atribución de racionalidad o irracionalidad de la creencia religiosa. De esta manera, ninguna evidencia epistémica externa hace racional o irracional a una creencia religiosa. En últimas, la relevancia pragmática de la atribución no tiene nada que ver con asuntos epistémicos y, por tanto, la tesis de la racionalidad pragmática es una tesis esencialmente anti-evidencialista, aunque satisface las demandas morales y éticas de las tesis evidencialistas.

El problema con el fundamentalista es que no podía ser desacreditado como irracional desde la perspectiva anti-evidencialista (o al menos no desde la postura de James). Sin embargo, no ocurre lo mismo bajo el concepto de racionalidad pragmática. A la luz de la tesis de la racionalidad pragmática de la creencia religiosa, el fundamentalista es claramente calificado como irracional, porque sistemáticamente socava las capacidades y virtudes identificadas en el mismo 
momento en que las quiere fomentar. En últimas, el fundamentalista es irracional porque mina la posibilidad de la vida humana misma. Ahora bien, ¿qué hacer con los textos sagrados que parecen implicar actitudes que no son consistentes con el marco normativo establecido? Al respecto, acudo a una distinción hecha por Rorty, a la que hice mención anteriormente, pero que especificaré de modo diferente. De acuerdo con Rorty, la diferencia entre un literalista (fundamentalista) y un simbolista, consiste en que el primero tiene compromisos metafísicos, mientras que el segundo no. Argumenté en contra de la posibilidad real de que las religiones fueran simbolistas en ese sentido. Sin embargo, la distinción puede mantenerse si se define en relación no con compromisos metafísicos, sino en virtud de la consistencia con el catálogo de las virtudes éticas. Cuando encontramos textos sagrados que explícitamente van en contra del catálogo de virtudes (el Antiguo Testamento está lleno de ellos, por ejemplo), podemos interpretarlos literalmente (caso en el cual seremos fundamentalistas). Pero los teólogos y religiosos también pueden interpretar los textos de manera simbólica, lo que quiere decir que encontrarán un modo en que la interpretación (no el texto literal) constituya un credo pragmáticamente racional. La racionalidad pragmática permitiría, sólo así, la coexistencia de sistemas de creencias religiosas inconsistentes entre sí, pero subdeterminados por una ética de las virtudes no relativas.

\section{REFERENCIAS BIBLIOGRÁFICAS}

Axtell, Guy. 2013. "Possibility and Permission? Intellectual Character, Inquiry, and the Ethics of Belief". En William James on Religion, editado por Henrik Rydenfelt y Sami Pihlström, 165-198. London: Palgrave Mcmillan.

Axtell, Guy. 2019. "An Inductive Risk Account of the Ethics of Belief". Философия. Журнал высшей школы экономики III (3):146-171.

Caruana, Louis. 2012. "Science, Religion and Common Sense". European Journal for Philosophy of Religion 4(4): 161-173.

Christian, Rose Ann. 2009. "Restricting the Scope of the Ethics of Belief: Haack's Alternative to Clifford and James. Journal of the American Academy of Religion 77(3): 461-493.

Clifford, William. 1877. "La ética de la creencia". En La voluntad de creer. Un debate sobre la ética de la creencia, editado y traducido por Lorena Villamil-García, 91-134. Madrid: Tecnos, 2003.

Haack, Susan. 1995, "El interés por la verdad: qué significa, por qué importa". En Teorías de la verdad del siglo XX, editado por María José Frápoli-Sanz y Juan Antonio Nicolás-Marín, 53-62. Madrid: Tecnos. 
Haack, Susan. 2003, "Point of Honor. On Science and Religion". En Defending Science - within Reason: Between Scientism and Cynicism, 265-297. New York: Prometheus Books.

Haack, Susan. 2009, “«The Ethics of Belief» Reconsidered”. En Evidence and Inquiry. A Pragmatist Reconstruction of Epistemology, 345-160. New York: Prometheus Books.

Haack, Susan. 2019. "Falibilismo y fe, naturalismo y lo sobrenatural, ciencia y religión”. En La racionalidad de la creencia religiosa, editado por Ángel Rivera Novoa y Andrés Buriticá, 19-35, Bogotá: Universidad Nacional de Colombia.

Hurtado, Lluís Miquel. 2017. "El ISIS asume el ataque de Estambul y amenaza a Turquía con más violencia". El Mundo, 02 de enero de 2017. Consultado el 19 de julio de 2017. http://www.elmundo.es/internacional/2017/01/02/ 5869636ae5fdeabe358b459f.html

James, William. 1897. "La voluntad de creer". En La voluntad de creer y otros ensayos de filosofia popular, traducido por Ramón Vilà-Vernis, 41-70. Bacerlona: Marbot Ediciones, 2009.

James, William. 1907a. "El significado del pragmatismo". En Pragmatismo. Un nombre nuevo para viejas formas de pensar, traducido por Luis Rodríguez, 51-75. Buenos Aires: Aguilar, 1973.

James, William. 1907b. "Concepción de la verdad según el pragmatismo". En Pragmatismo. Un nombre nuevo para viejas formas de pensar, traducido por Luis Rodríguez, 155-181. Buenos Aires: Aguilar, 1973.

Leitgeb, Hannes. 2017. The Stability of Belief: How Rational Belief Coheres with Probability. Oxford: Oxford University Press.

Moss, Sarah. 2018. Probabilistic Knowledge. Oxford: Oxford University Press.

Nottelmann, Nikolaj y Fessenbecker, Patrick. 2019. "Honesty and Inquiry: W. K. Clifford's Ethics of Belief". British Journal for the History of Philosophy: 1-22.

Nussbaum, Martha. 1992. "Human Functioning and Social Justice: In Defense of Aristotelian Essentialism". Political Theory 20(2): 202-246.

Nussbaum, Martha. 1996. "Virtudes no relativas: un enfoque aristotélico". En La calidad de vida, editado por Martha Nussbaum y Amartya Sen, 318-351, México: Fondo de cultura económica, 2004.

Pettigrew, Richard. 2016. Accuracy and the Laws of Credence. Oxford: Oxford University Press.

Plantinga, Alvin. 2000. Warranted Christian Belief. Oxford: Oxford University Press.

Rivera-Novoa, Ángel. 2017. "Creencias religiosas, inefabilidad y verdad". Franciscanum. 168, Vol. LIX: 23-61.

Rivera-Novoa, Ángel. 2020. "Rorty's Demands on Religious Belief: In Search of a Pragmatic Rationality". En Revisiting Richard Rorty, editado por Pedro Moreira, 205-217. Málaga: Vernon Press. 
Rorty, Richard. 1994. "Religion as Conversation-stopper". En Philosophy and Social Hope, 168-174, London: Penguin Books, 1999.

Rorty, Richard. 1999. "Religious Faith, Intellectual Responsibility and Romance". En Philosophy and Social Hope, 148-167, London: Penguin Books.

Rorty, Richard. 2000a. "Pragmatismo y Religión”. En El pragmatismo una versión. Antiautoritarismo en epistemología y ética, traducido por Joan VergésGifra, 21-48. Madrid: Ariel.

Rorty, Richard. 2000b. "El pragmatismo como un politeísmo romántico" . En El pragmatismo una versión. Antiautoritarismo en epistemología y ética, traducido por Joan Vergés-Gifra, 49-77. Madrid: Ariel.

Rorty, Richard. 2003. "Religion in the Public Square. A reconsideration". Journal of Religious Ethics 31(1): 141-149.

Smith, Martin. 2017. Between probability and certainty: What justifies belief. Oxford: Oxford University Press.

Wittgenstein, Ludwig. 1966. Lecciones y conversaciones sobre estética, psicología y creencia religiosa, traducido por Isidoro Reguera. Barcelona: Paidós, 1992.

Wittgenstein, Ludwig. 1967. Observaciones a La rama dorada de Frazer, traducido por Javier Sábada. Madrid: Tecnos, 1992.

Zambrana, Marga. 2017. "El ISIS asume el ataque de Estambul y amenaza a Turquía con más violencia". El País, 02 de enero de 2017. Consultado el 19 de julio de 2017. http://internacional.elpais.com/internacional/2017/01/02/ actualidad/1483345765_683112.html

Ángel Rivera-Novoa

Instituto de Filosofía Universidad de Antioquia Calle 67 No. 53-108, Bloque 12

Medellín (Colombia) https://orcid.org/0000-0001-6793-0307 